\title{
Configuración contemporánea del capitalismo en Nuestra América: determinaciones para el Trabajo Social
}

\section{Contemporary configuration of capitalism in Our America: Determinations for Social Work}

\author{
Ramiro Marcos Dulcich Piccolo ${ }^{a}$
}

\begin{abstract}
Resumen
El texto se propone reflexionar sobre las determinaciones históricas del capitalismo contemporáneo en Nuestra América, como base para el debate sobre los desafíos del Trabajo Social en la región. Por contradicciones propias de su fase madura, el capitalismo se reproduce al costo de niveles crecientes de destructividad social y ambiental, afirmándose en tendencias regresivas y controladoras que deshumanizan el ser social. El retorno de la hegemonía neoliberal en Nuestra América desató un proceso de deshumanización, de barbarización de la vida social, que tiene por raíz la destrucción de fuerza viva de trabajo a través del desempleo. Este contexto amenaza la consolidación de los proyectos profesionales críticos en el Trabajo Social. Restricciones en la autonomía relativa en su trabajo, precarización de contratos, escasez de recursos e inestabilidad demarcan los espacios ocupacionales. El re-ascenso de los movimientos sociales puede contribuir con la formulación de respuestas para redefinir los márgenes del ejercicio profesional.
\end{abstract}

Palabras clave: capitalismo contemporáneo, cuestión social, estado, proyecto profesional crítico del trabajo social.

\begin{abstract}
The text intends to reflect on the historical determinations of contemporary capitalism in Our America, as the basis for the debate on the challenges of Social Work in the region. Due to contradictions of its mature phase, capitalism reproduces itself at the cost of increasing levels of social and environmental destructiveness, affirming itself in regressive and controlling tendencies that dehumanize the social being. The return of neoliberal hegemony in Our America unleashed a process of dehumanization, of barbarization of social life, which has as its root the destruction of the living force of work through unemployment. This context threatens the consolidation of critical professional projects in Social Work. Restrictions on the relative autonomy in their work,
\end{abstract}

a Universidad Federal Fluminense (UFF), Brasil.

Correspondencia a: dramiro3@gmail.com

Recibido:

17 julio 2018

Aceptado:

1 octubre 2018

Artículo publicado en acceso abierto bajo la Licencia Creative Commons.

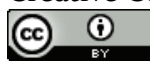

Cita:

Dulcich Piccolo, R. M

(2018). Configuración contemporánea del capitalismo en Nuestra América: determinaciones para el Trabajo Social. Kera Yvoty: reflexiones sobre la cuestión social, 3, 75-85. 
precariousness of contracts, scarcity of resources and instability demarcate the occupational spaces. The re-promotion of social movements can contribute to the formulation of responses to redefine the margins of professional practice.

Keywords: contemporary capitalism, social issue, state, critical professional project of social work.

\section{Introducción}

De acuerdo con el análisis de geógrafo crítico norte-americano David Harvey (2005), a lo largo de su proceso de "ascenso histórico" el capitalismo ha logrado fugarse de las crisis que cíclicamente lo azotan a través de sucesivas expansiones de su ambiente, extendiendo sus fronteras. Las distintas fases experimentadas por el capitalismo retratan un proceso de estiramiento de sus límites. Desde hace algunas décadas, varios críticos vienen alertando de que el sistema sufre de un agotamiento histórico, lo que marcaría su decadencia en tanto proyecto civilizatorio; su imposibilidad de cumplir las promesas de desarrollo y de progreso social.

En la misma línea, el húngaro marxista István Meszáros (2002) plantea que el capitalismo contemporáneo revela que alcanzó ciertos límites absolutos, que no son resolubles dentro de la lógica del capital. Para este autor, la activación de estos límites a finales de la década de 196o evidencia el carácter estructural de la actual crisis sistémica. Por un lado, vemos el grado más avanzado de desarrollo las fuerzas productivas sociales, capaz de reducir el hambre y el tiempo de trabajo; sin embargo, se instala como crónico el fenómeno de la súper-población relativa, desempleada estructuralmente, lanzada al pauperismo y sin condiciones mínimas de reproducir su ser.

La irrupción de esta crisis estructural a inicios de la década de 1970 demandó la redefinición urgente de elementos medulares del sistema, que tuvo como eje un severo "ajuste de cuentas" con el trabajo. El llamada "crisis del mundo del trabajo", con la instalación de un desempleo crónico, es expresión de éste proceso que determina fuertemente la sociabilidad contemporánea. Para recomponer la tasa de ganancia y subsistir en el mercado mundial, el capital precisó desmontar las formas de organización de la producción del periodo fordista y desarrollista, introduciendo la flexibilización del mercado de trabajo y un desempleo permanente que expresa la consolidación de una población estructuralmente excedente.

A diferencia de los "30 años gloriosos" del capitalismo de pos- II Guerra Mundial, estas personas dejan de ser "necesarias" del punto de vista de la producción, como resultado de las incesantes innovaciones tecnológicas. Varios autores han llamado a este fenómeno de "exclusión social", coincidiendo en que es un punto de pauta central para el Trabajo Social, puesto que redefine la "cuestión social" y renueva sus formas de expresión, las que constituyen el objeto de nuestra intervención profesional. Con la entrada del capitalismo en su crisis estructural ocurre una renovación de las manifestaciones de la desigualdad social, diferente de la fase histórica anterior. Aparecen nuevas determinaciones históricas (como el desempleo estructural) en la dinámica conflictiva de la reproducción social, así como son alteradas las respuestas estatales para tratarla.

De éste modo, entendemos que la particularidad de la "cuestión social" contemporánea tiene que ver con el conjunto de impactos provocados por la recomposición del capital desde 1970 hasta hoy, asentada en una ofensiva contundente sobre el trabajo. El trabajo asalariado, en tanto forma "oficial" de realizar la reproducción del ser en la sociedad capitalista, se torna un privilegio.

De modo que, la respuesta del capital a la crisis estructural se basó en 
la precarización de fuerza de trabajo y generó una masa creciente de individuos "no necesarios" aunque funcionales. La producción de esta población excedente se realiza como un verdadero proceso de barbarización de la vida social, produciendo subjetividades mutiladas por el "tiempo libre frustrado” por el desempleo crónico. Estas masas que flotan diseminadas globalmente por el sistema - no sólo en las periferias - se tornan un desafío gigantesco de administrar y tensiona la demanda por el Trabajo Social.

\section{El Estado capitalista y sus metamorfosis}

Al analizar las profundas transformaciones societarias neoliberales, puede verse que el Estado aparece siempre como un instrumento fundamental, un momento constitutivo de la realidad social. Desde sus inicios del modo de producción capitalista, el Estado fue necesario para viabilizar su desarrollo; una condición indispensable, podríamos decir; sin dudas, el instrumento de intervención social y política por excelencia, imprescindible para mantener y expandir una sociedad de clases. Un capitalismo sin Estado, sin esta mediación que institucionaliza formas jurídicas, políticas e ideológico-culturales, la reproducción de las relaciones sociales entre las clases sería imposible.

Sobre el moderno Estado capitalista, dirá el filósofo húngaro:

La formación del Estado moderno es una exigencia absoluta para asegurar y proteger permanentemente la productividad del sistema. El capital llegó al dominio del reino de la producción material paralelamente al desarrollo de las prácticas totalizadoras que dan forma al Estado moderno. Por lo tanto, no es accidental que el cierre de la ascensión histórica del capitalismo en el siglo XX coincida con la crisis del Estado moderno en todas sus formas, desde los Estados de formación liberal- democrática, hasta los Estados capitalistas de extremo autoritarismo; desde los regímenes pos-coloniales, hasta los Estados pos-capitalistas de tipo soviético. Comprensiblemente, la actual crisis estructural del capital afecta con profundidad todas las instituciones del Estado y los métodos organizacionales correspondientes. (Mészáros, 2002, p. 106)

Para el autor, el Estado moderno se constituye en una estructura correctiva que es compatible con las exigencias de la reproducción del capital, cuya función esencial es rectificar - hasta donde los límites de la acumulación lo permitan -, las contradicciones y conflictos que emergen en la dinámica social. Desde el punto de vista jurídico-legal, el Estado es una exigencia absoluta para la reproducción de las relaciones sociales capitalistas; surge como una necesidad material efectiva del orden que pasa a ser una precondición para su articulación continua y para la organización permanente del conjunto.

Con la hegemonía de los neoliberales y la implantación de sus políticas, la modalidad de operar la reproducción social es radicalmente modificada. La lógica que movía a la fase histórica del programa Fordista-Keynesiano (19301970), norteado por el interés de "integrar" a las diferentes camadas de la clase trabajadora al funcionamiento sistémico, inclusive en buena parte de las periferias, (con la industrialización por sustitución de importaciones y el programa del "desarrollismo"), tenía como objetivo expreso internalizar los conflictos sociales e institucionalizar las reivindicaciones de los movimientos y organizaciones populares, de modo que se pudiera integrarlas funcionalmente al desarrollo del capital. La creación de un conjunto de instituciones y políticas sociales significó el reconocimiento de ciertos derechos humanos elementales (la ciudadanía) por los Estados capitalistas más "progresistas" del mundo.

Las propuestas regulacionistas 
y distributivas, que apuntan a un "capitalismo humanizado", por algunos años consiguieron conciliar desarrollo económico con la paz social, a través del establecimiento de políticas sociales de asistencia para los pobres, así como un ascendente consumo y otras mejoras importantes en las condiciones de vida de la clase trabajadora. El Estado, entonces, fue comprometido con la promoción del "bien común", el "buen vivir", aunque dentro de los límites tolerables por la valorización del capital. Fue movilizado para garantizar la satisfacción de necesidades básicas de los ciudadanos con su intervención, constituyéndose en una palanca importante para alcanzar el "progreso social".

La crisis del patrón keynesiano de acumulación exigió una respuesta histórica del conjunto de las clases capitalistas, donde el Estado fue responsabilizado por las contradicciones y llamado resignificar su intervención social, en función de cumplir con las nuevas funcionalidades exigidas por el proceso de reproducción de las relaciones sociales bajo la hegemonía neoliberal: maximizar la tasa de ganancia de los capitales.

En la actualidad, en tanto sistema económico mundialmente articulado, percibimos que el capitalismo deshizo las estructuras tradicionales de estratificación y controles sociales (y políticos) históricamente formados en la fase "progresista". Esta descomposición de las formas tradicionales de ejercer el control social no aparece estar acompañada de un nuevo sistema de control efectivo, aglutinador, que permita una acumulación tranquila del capital a escala mundial.

\section{Las "ruinas" de la Política Social}

De acuerdo con la investigadora brasilera Elaine Behring (1998), la aguda crisis capitalista de 1929-1932 es el ápice de un largo periodo "depresivo" que genera serias preocupaciones para las burguesías que comienzan a desconfiar de la eficacia de los "automatismos del mercado" en la regulación de la vida social. La clase capitalista sintió en la piel los riesgos de enfrentar una crisis de esa naturaleza, de esa intensidad y extensión, en un escenario mundial polarizado por el avance del proyecto socialista, a partir de la primera experiencia histórica victoriosa con la Revolución Rusa. Este contra-peso político, económico y militar, desafió la formulación de una respuesta a la altura, una "contestación burguesa" al liberalismo, una auto-reforma del capitalismo, que fue estructurada a partir de la teoría keynesiana, que recogía los resultados del New Deal norteamericano frente a la crisis de 1929.

Para los keynesianos era posible estabilizar los antagonismos del sistema del capital y administrar su despliegue a través de la planificación y organización del ciclo económico. La estrategia keynesiana articulaba un complejo de medidas "anti-crisis", que buscaban prevenirlas interfiriendo directamente en el ciclo económico cuando este mostrase señales de agotamiento o mal funcionamiento. Se buscaba regular los ciclos de reproducción del capital para evitar las crisis. Esta reforma del capitalismo rompe con la ortodoxia liberal y prepara el terreno para un cambio ideológico y de valores, que legitiman la estrategia de contener las contradicciones sociales aumentando el consumo, por la vía de la intervención estatal y de políticas sociales.

De este modo, a partir de 1929 surgen y se multiplican los "seguros sociales" como expresiones de un nuevo patrón de "protección social" para los trabajadores. Inicialmente como repuesta a presiones de las organizaciones sindicales, estos dispositivos asistenciales emergen para enfrentar el desempleo, la invalidez, las enfermedades, la vejez, buscando superar la caridad y la beneficencia privadas. Son creadas "Cajas" para cubrir pérdidas y diversos fondos para todo tipo de pérdida de salario. Para Behring (1998), una concepción de Seguridad Social va instalándose, al mismo tiempo que el sentimiento "de clase" impregna los programas de los trabajadores, 
que tratan por todos los medios de evitar la producción de un "sub-proletariado" que pese sobre el salario.

Es en este contexto que emergen las políticas sociales, como herramientas de la política keynesiana de integración social, elevación de la "demanda global" y aumento del consumo, con el Estado en la "planificación económica" del proceso. Las políticas sociales se constituyen como productos resultantes de las contradicciones de este orden social, cuyas formas histórico-específicas asumidas se encuentran determinadas por las correlaciones de fuerzas políticas entre las clases sociales, en coyunturas y territorios particulares. El pacto social entre las clases es asegurado con la política salarial y el control de precios, con una política fiscal progresiva y oferta de créditos y de tasas de interés viables.

A pesar de su éxito relativo, la “estrategia keynesiana” encontró límites estructurales. Para Bhering (1998), la búsqueda de "súper-lucros" - que impulsa el proceso de innovación tecnológica y su generalización -, sumado a la ampliación de la resistencia política de los trabajadores y la intensificación de la "monopolización" del proceso de concentración del capital, determinaron una "nueva depresión" a finales de 1960. El "mar de deudas" y la inflación se tornaron agravantes que precipitaron la crisis estructural.

A partir de entonces, una nueva modalidad de organizar la reproducción de la vida social es diseñada. La misma expresa la alteración sustancial de algunos parámetros fundamentales del orden social, emergiendo fenómenos sociales "nuevos" que demandan respuestas. El fordismo-keynesiano, en tanto paradigma estructurante del "mundo capitalista”, es fuertemente cuestionado. El modelo de regulación social del conflicto de clases (a través de la negociación) que logró administrar el sistema por más de 30 años se tornó un peso muerto para el capital, que luchaba contra la depresión de su tasa de ganancias.

Dentro del conjunto de instrumentos de control social redefinidos para garantizar la reproducción de las relaciones sociales neoliberales se destacan las políticas sociales. El análisis de las metamorfosis experimentadas por las mismas-y por el conjunto de prácticas que se congregaron a su alrededor en la fase anterior del sistema, donde vivenciaron su auge - es indispensable para entender las determinaciones contemporáneas del ejercicio profesional y pensar estrategias de intervención.

Son aplicados criterios de selectividad para responder a derechos universales conquistados, al mismo tiempo en que son transferidos para la esfera privada la satisfacción de necesidades sociales elementales. Una parcela significativa de la prestación de servicios sociales es transferida del Estado para una abstracta "sociedad civil" o para el mercado, afectando seriamente el espacio socio-ocupacional de varias categorías profesionales, entre estas, el Trabajo Social.

De acuerdo con Soares (2000), las políticas sociales universalistas de los llamados Estados de Bienestar Social, fundamentalmente de responsabilidad pública-estatal, son redefinidas a partir de criterios como focalización (emergencialidad) y descentralización (recorte de gastos vía evacuación de competencias hacia otras instancias de la sociedad). Son conceptos de un programa que apunta a la reducción de los gastos públicos (inclusive, son funcionales a la manutención del precio de la fuerza de trabajo por debajo de su valor), bajo la premisa de que las necesidades sociales (demandas profesionales) son responsabilidad exclusiva de los portadores, quedando en el espacio de la auto-ayuda y la ayuda mutua la resolución de las mismas.

Esta nueva modalidad de tratar la “cuestión social" presenta dostendenciasa la privatización: por un lado, variasactividades y competencias situadas en la órbita de la "esfera pública-estatal" son trasferidas a una variedad enorme de organizaciones de la "sociedad civil" (las ONGs) en una 
suerte de "re-filantropización" del trato a la "cuestión social"; por otro, la atención de determinadas necesidades - especialmente aquellas con más potencial de rentabilidad, salud, educación, previsión social - es directamente mercantilizada.

Porciones importantes de las políticas sociales son mercantilizadas y subsumidas a la lógica de la valorización del capital; dejan de expresar "derechos" y son arrojados al mercado, al circuito de compra-venta de productosyservicios. Dichamercantilización hace que los "derechos sociales" se reduzcan a "derechos del consumidor" (de aquellos que pueden comprarlos) y el dinero pasa a intermediar la prestación de lo que antes eran servicios públicos.

De modo que, con la privatización de las políticas sociales ocurre una progresiva mercantilización de la atención a ciertas necesidades sociales potencialmente lucrativas, así como la evacuación de programas y servicios sociales de responsabilidad público-estatal hacia una nebulosa "sociedad civil". Retiradas de la órbita del Estado; trasferidas al mercado o al "tercer sector", las políticas sociales son privatizadas. La nueva funcionalidad atribuida a las mismas se caracteriza por la primacía de programas asistenciales de carácter emergencial, focalmente dirigidos a los más pobres.

Podemos afirmar, entonces, que ésta modalidad de intervención socio-estatal sobrelasexpresionesrenovadasypotenciadas de la "cuestión social" contemporánea apunta más a contener y administrar las secuelas sociales más desestabilizadoras del sistema que a superarlas a través de negociaciones. La respuesta a la "cuestión social" apela, nuevamente, a la filantropía y al voluntarismo. Dichos procesos afectan el significado social de la profesión de Trabajo Social, sin alterarlo en su esencia.

\section{Neoliberalismo y Nuestra América}

Al analizar la formación históricoconcreta de los países latino-americanos, puede percibirse claramente que el
Estado asume fisonomías diferentes en las diferentes regiones del sistema-mundo capitalista. En los países considerados "desarrollados", por ejemplo, el Estado se configura de forma muy diferente que en la periferia latinoamericana, debido especialmente al lugar ocupado en la división internacional del trabajo. De modo que, el análisis precisa rescatar la dialéctica del desarrollo desigual y combinado, como camino para comprender las relaciones entre los países y bloques que habitan el sistema mundial. Por esto, pensamos que vale la pena el esfuerzo por captar las particularidades históricas que el Estado adopta en cada territorio, puesto que expresa la modalidad histórica de organizar la subordinación del trabajo al capital.

$\mathrm{Si}$ observamos la configuración estatal que complementó la implantación del neoliberalismo en los países del capitalismo central, veremos que dista mucho del papel que el estado jugó en las regiones "subdesarrolladas" del sistema y las periféricas. Mientras que en los "centros" del mundo capitalista el pasaje del Welfare State para el Estado neoliberal (que implicó el desmonte de consensos y la construcción de compromisos sociales), coincide con una política monetarista y de subsidios a las nuevas industrias en desarrollo, bien como con una Seguridad Social de mayor selectividad (en cuanto a sus políticas educativas, asistenciales), en las periferias los procesos de "ajuste estructural", con privatizaciones implementadas "sin anestesia" y metas de austeridad en el gasto social, provocan impactos catastróficos que son resistidos por los pueblos.

La actual industrialización destructora de fuerza de trabajo humana agudiza la "cuestión social" y la respuesta estatal se limita al enfrentamiento de las manifestaciones sociales más críticas de la crisis, por medio de la generalización de programas asistenciales y otros dispositivos desplegados para contener a los "excluidos estructurales" y administrar las tendencias a la barbarización de la sociedad. La concepción más amplia de Seguridad Social 
(como sistema de protección) es reducida a la Asistencia Social, consolidando un nuevo paradigma de políticas sociales funcionales y compatibles con los principios neoliberales; el complemento junto para neutralizar las manifestaciones más "explosivas".

En Nuestra América, después de algunas décadas de intentos de restituir el modelo productivo industrial tendiente al pleno empleo, parece inviable para el capitalismo convivir con el llamado "Estado de Bienestar Social" de la segunda posguerra. La sociedad de mercado globalizada no soporta el tipo de tributación progresiva exigida por aquella "regulación macrosocietaria", ni admite ya planificación duradera que represente un freno a la libre acumulación monopolista del capital. El "Estado de Bienestar Social", en tanto modelo de regulación de la economía por la política, habría sido históricamente superado, por la imposibilidad sistémica de garantizar niveles de igualdad sustantiva.

El desmonte del llamado Estado interventoren América Latina, lejos dellevar a la prosperidad y de producir escenarios sociales de mayor tranquilidad, tal como se esperaba, significó un auténtico proceso regresivo para la sociedad, un verdadero proceso de barbarización de la vida; las promesas de progreso y de justicia social son lejanos ecos resucitados para campañas electorales. Más allá de las apariencias de los discursos apologistas del neoliberalismo, es fundamental comprender cómo la programática neoliberal ha transformado a Nuestra América en las últimas décadas.

El conjunto de trasformaciones societarias operadas en la enorme mayoría de los países latinoamericanos desde la década de 1970, en el marco de la respuesta del capital a su aguda crisis estructural, presentadas como un paquete de "reformas necesarias e infalibles", redundaron en una verdadera catástrofe societaria para las mayorías sociales del continente. Dicha "catástrofe social" resultante de las políticas neoliberales, en la década de 1990 permitió que, contradictoriamente, emergieran diversas fuerzas, grupos sociales $y$ sectores de clase, dispuestos a resistir las envestidas del capital, con diversas tácticas y expresiones locales, nacionales y regionales.

Lo que América Latina vive en los últimos años es un claro proceso de emergencia y explicitación de las luchas sociales contra las lógicas neoliberales; un auténtico movimiento de re-ascenso de los conflictos y las luchas a lo largo y a lo ancho de todo el continente. A su vez, esto ocurre luego de la fase de terror de Estado de las décadas de 6o, 70 y parte de 1980, aplicada por las clases dominantes locales (en estrecha asociación con el imperialismo norteamericano) para contener la radicalización de las luchas de liberación y lograr implementar el programa neoliberal para recomponer la tasa de ganancia del capital.

Este ascenso del ciclo de luchas sociales pos-terrorismo de Estado y contra el neoliberalismo se difunde continentalmente y promueve procesos de unificación e identificaciones. Lo que unifica es la resistencia al imperialismo neoliberal. Su enfrentamiento de yergue como el nexo más claro para definir el tipo de unidad de Nuestra América, desafiada por la contundencia del genocidio económico que azota la región desde su génesis como colonia del naciente capitalismo.

El neoliberalismo, por tanto, no es sólo un modelo injusto de acumulación económica y distribución de riqueza, el cual fácilmente podría ser reemplazado por otro con "voluntad política" gubernamental. Es, ante todo, el resultado histórico de los grandes enfrentamientos sociales y políticos que conmocionaron el mundo en las décadas de 1960 y 1970. Además, la fase neoliberal profundiza los problemas de la periferia, puesto que es allí donde el sistema "oxigena" sus crisis de desvalorización. Es en las periferias del sistema donde primeramente se descarga el peso destructivo y cada vez más violento de las crisis del capital; sobre éstas han sido realizados históricamente los 
"ajustes estructurales" necesarios para la renovación del vigor de la acumulación y la recomposición de la tasa de lucros.

En este sentido, la contundencia del "fracaso de la "promesa civilizatoria neoliberal" coloca en pauta la necesidad de formular alternativas a las fuerzas que resisten. Hoy podemos encontrar en Nuestra América procesos sociales y fuerzas de resistencia a los procesos de la expansión insaciable del imperialismo capitalista, que son laboratorios de experiencias pos-neoliberales que se desarrollan cuestionando las bases socio-económicas y políticas del régimen. Agitadas jornadas de lucha social ganan intensidad al ritmo de una nueva fase de agudización de las contradicciones sistémicas y de alcance de la activación de sus "limites estructurales".

\section{Impactos en el significado de la profesión y formulación de alternativas}

Como fue apuntado, como consecuencia de la profundización de las políticas neoliberales, el pauperismo en la masa trabajadora agravó la "cuestión social”, particularmente en América Latina, donde se registra la presencia creciente de todo tipo violencias. Para trabajar en su contención y administración adecuada varios dispositivos del "control social" serán demandados, entre los que encuentra la profesión de Trabajo Social.

El análisis de la actual demanda profesional, aquello que se nos demanda en el trabajo, permite develar el significado social de nuestras intervenciones, del punto de vista de las instituciones empleadoras. Lo que emerge de este análisis es la identificación de la profesión de Trabajo Social con un ejecutor terminal de políticas sociales, de acuerdo con la expresión clásica de J. P. Netto (1997). La demanda profesional del neoliberalismo minimiza la funcionalidad de la profesión, reduce sus potencialidades transformadoras, readecuándola a las condiciones históricas digeribles por el sistema.

Por esta vía, con la presión del mercado de trabajo en sus espaldas, la formación profesional es influenciada por parámetros tecnicistas y "productivistas" propios del capitalismo maduro. De esta forma, la tendencia a reducir el Trabajo Social a un administrador de la "cuestión social” cobra vigor y gana espacio dentro del ámbito profesional". Los avances producidos por los segmentos críticos de la categoría en las últimas décadas, desde la Reconceptualización, entran en contradicción con esta tendencia general del sistema, moviéndose en la contra mano de los proyectos societarios hegemónicos.

En esta perspectiva, es esperable que las transformaciones profesionales en curso, como resultado de la demanda del estado neoliberal, se materialicen como restricción de autonomía relativa del profesional en la organización de su proceso de trabajo. La corrosión del mercado de trabajo profesional, la precarización de las instituciones y de las políticas sociales redimensionan los espacios sócioocupacionales, estrechando los márgenes para intervenciones más profundas. Todo indica que la profesión es por diversas instancias institucionales del Estado, del sector privado y del espacio "público noestatal”, para participar en la ejecución de políticas sociales destinadas a administrar una crisis permanente.

De acuerdo con el análisis crítico del brasilero J. P. Netto (1999), la contradicción fundamental que hoy enfrentan los proyectos profesionales que van a contramano del proyecto societario hegemónico se centra en el problema del mercado de trabajo profesional y las atribuciones/ papeles profesionales requeridos. Este es, sin dudas, el mecanismo de ajuste y disciplinamiento más efectivo para garantizarel proceso de reproducción social, ajustando funcionalmente las prácticas profesionales a las exigencias sistémicas del capitalismo en crisis estructural.

Su ineludible condición de trabajador 
asalariado, dependiente de las oscilaciones del mercado de trabajo, es el más difícil de los desafíos contemporáneos del proyecto profesional crítico en Nuestra América, cuestión en la cual se articulan recíprocamente proyecto profesional y proyecto societario. En esta perspectiva, en tanto los proyectos societarios alternativos continúen frágiles e inconsistentes, la demanda estatal a la profesión será para actividades de "control y administración social”, perfeccionando los dispositivos de ajuste.

La crisisy/o fragilidad de los proyectos societarios alternativos, por otra parte, abre espacio para que se afirme una actitud conservadora de "subordinación sutil a lo dado” en el ámbito profesional, que opera a partir del miedo al desempleo estructural. Se realiza una adecuación minimalista a los nuevos tiempos en parte de la categoría de los Trabajadores Sociales, donde el alivio de lo extremo es la justificativa para mantener el satus quo.

No obstante este contexto, son varias las experiencias profesionales que con grados de eficacia diferentes intentan vincular su actividad profesional a un proyecto de sociedad alternativo al status quo. Existen hoy en América Latina proyectos profesionales contrarios a las políticas neoliberales; proyectos que buscan trascender el actual modo de organización de la vida social y la destrucción de vidas humanas que conlleva.

$\mathrm{Si}$ el orden de cosas es naturalizado por las conciencias de los individuos sociales, todo seguirá su absurdo "cauce natural" y la categoría, mayoritariamente, se verá administrando la barbarie. Es este el principal dilema del proyecto profesional crítico en Nuestra América contemporánea. La búsqueda por superarlo es un desafío gigantesco.

Entendemos que la contradicción entre el avance del proyecto profesional crítico y la vigencia del proyecto societario neoliberal muestra el tamaño de los desafíos que enfrentamos. Su consolidación a escala regional no puede ser pensada ni podrá darse aisladamente de las condiciones y la suerte de las fuerzas socio-políticas que disputan proyectos societarios en los diferentes países de Nuestra América, bien como en la totalidad del sistema- mundo.

\section{Conclusiones}

Este ensayo permitió observar como la actual coyuntura socio-histórica en Nuestra América vuelve a ser hegemonizada por las políticas neoliberales, ajustadas a las necesidades del gran capital. Un declino del poder del imperialismo norte-americano frente a China y otros bloques en el sistema económico mundial, paralelamente a la reaparición de actores de peso como Rusia, han reducido los márgenes del Imperio en la región que domina hace más de un siglo.

Los imperativos de las ganancias capitalistas en un mercado internacional cada vez más agresivo, exigen un endurecimiento de las relaciones imperialistas con la región. La reorientación agresiva de las políticas imperialistas en Nuestra América muestra los obstáculos que enfrentan las experiencias "neodesarrollistas" para mantener un crecimiento capitalista con ciertos niveles de "re-distribución" de la riqueza nacional, controlando las exigencias de la acumulación.

En esta perspectiva, entendemos que las políticas actuales generan procesos de degradación de la vida social en todo el mundo, que barbarizan las sociedades. Con la crisis estructural del capitalismo emergieron un conjunto de importantes transformaciones societarias que reconfiguraron la "cuestión social" y sus manifestaciones, donde se destaca el proceso de destrucción de fuerza viva de trabajo que lleva a la precarización de las condiciones de vida de la gran mayoría de la población. Destrucción de humanidad y barbarización de la vida social se tornan necesarias para la valorización del capital en la contemporaneidad. La triste confirmación de que estamos ante una crisis "crónica" activó un conjunto de dispositivos destinados a viabilizar el proceso de 
la reproducción social, adaptando sus funciones a las exigencias de la realidad sistémica.

El Trabajo Social, en tanto especialización del trabajo colectivo, no es ajeno a ese contexto y será tensionado en algunos principios fundamentes y en sus bases materiales. En tanto trabajo asalariado, inscripto en la división socio-técnica del trabajo de la sociedad capitalista, la actividad profesional es un "trabajo alienado"; o sea, no es una actividad libre y voluntaria; no es el profesional quien define los objetivos de su actividad; quien organiza lo que hace es el empleador: el Estado mayoritariamente. Esto nos lleva a pensar sobre el producto de su trabajo. Como vimos, se instala un tipo de intervención estatal ante la "cuestión social" cuya finalidad principal es administrar el proceso creciente de "polarización social", de profundización de las desigualdades que conduce a la barbarie.

Vimos, también, que en la sociedad entran en disputa proyectos en disputa, que se expresan en el interior del ámbito profesional y provocan disputas en torno de la orientación que debe asumir el proyecto profesional del Trabajo Social en cada momento histórico. El espacio profesional está lejos de ser homogéneo sobre las concepciones de mundo y los compromisos con los proyectos societarios más generales. El análisis de las correlaciones de fuerzas políticas en el continente, entre los diferentes proyectos societarios presentes en Nuestra América hoy es fundamental para reflexionar sobre el colectivo profesional crítico en el entramado de relaciones de la sociedad como una totalidad concreta y proyectar iniciativas históricas desde su lugar.

Sustentamos como hipótesis de este ensayo que la crisis estructural del sistema determinó ondas transformaciones en el significado y funcionalidad social de la profesión de Trabajo Social, a partir de la redefinición de su demanda histórica por exigencias productivistas de administración y control social. También, la modalidad de intervención socio-estatal ante la "cuestión social" fue radicalmente alterado; las mutaciones ocurridas en las políticas sociales, especialmente el proceso de des-universalización de las mismas, con la introducción de los criterios de focalización. De forma concomitante, la flexibilización del trabajo impone más restricciones en la autonomía relativa del ejercicio profesional. De modo que, las reestructuraciones capitalistas neoliberales afectan directamente la dimensión política del trabajo profesional.

En este sentido, pensar la profesión en el conjunto de la clase trabajadora, sufriendo el mismo proceso de precarización de las condiciones de trabajo (ya sea por la flexibilización de los contratos y/o el desempleo relativo en la categoría; o por la precarización de la respuesta estatal a la "cuestión social", en términos de políticas sociales. La articulación de los segmentos críticos del Trabajo Social más allá de las fronteras nacionales puede ser un insumo importante para la defensa de principios éticos y políticos de este colectivo profesional.

Percibimos claramente, también, que el ámbito de la formación profesional es influenciado por el contexto neoliberal y presenta grandes desafíos. Por un lado, no puede negarse los requerimientos de la demanda por este profesional, pues debe responder con eficacia para mantener su contrato de trabajo. No obstante, los riesgos de reproducir la actual demanda (de administración de una crisis social eterna) saltan a la vista. Una nueva onda de modernización conservadora pretende reinstalarse en el ámbito profesional en Nuestra América. Las estrategias de resistencia a estas tendencias empobrecedoras del ejercicio profesional, especialmente aquellas que buscan recuperar la dimensión colectiva, comunitaria del trabajo, son esfuerzos que hay alimentar.

En un momento histórico donde la crisis se torna permanente, con expresiones cada vez más violentas; donde las 
modalidades de regulación del conflicto entre las clases sociales vía integración asalariada parecen no ser más viables históricamente; donde el Estado inhibe sus funciones de "garantizarelbienestarcomún" en nombre de la austeridad y reconvierte su accionar en función de las exigencias de la reproducción ampliada del capital; donde los aspectos represivos y alienantes del "control social" del sistema se refuerzan, nos interrogamos sobre el significado social del Trabajo Social, destacando los riesgos de ser instrumentalizado para administrar la barbarie contemporánea.

\section{Referencias Bibliográficas}

Behring, E. (1998). Política Social no capitalismo tardio. São Paulo: Cortez Editora.
Harvey, D. (2004). O novo imperialismo. São Paulo: Edições Loyola.

Mészáros, I. (2002). Para além do capital. Rumo a uma teoria da transição. São Paulo: Boitempo Editorial, Editora da UNICAMP.

Netto, J. P. (1997). Capitalismo monopolista y servicio social. São Paulo: Cortez Editora.

Netto, J. P.(1999). A construção do projeto ético-político do serviço social. Módulo I de capacitação em serviço social e política social. Brasília: CFESS/ ABEPSS/CEAD/UnB.

Soares, L. T. (200o). Os custos sociais do ajuste neoliberal na América Latina. São Paulo: Cortez Editora.

\section{Sobre el Autor}

Ramiro Marcos Dulcich Piccolo

Profesor asociado del Departamento Interdisciplinario de la Universidad Federal Fluminense (UFFBrasil), Campus Rio das Ostras (RJ). Licenciado en Trabajo Social (UNR-Argentina). Doctor en Trabajo Social (UFRJ-Brasil). 